\title{
A dimensão educativa da educação não escolar: tem sentido este debate?
}

\author{
The educational dimension of non-school education: \\ does this debate make sense?
}

\section{La dimensión educativa de la educación no escolar: ¿tiene sentido este debate?}

\author{
Eliana Perez Gonçalves De Moura ${ }^{1}$ \\ DINORA TEREZA ZUCCHETTI ${ }^{1} 1$ \\ ${ }^{1}$ Universidade Feevale, Novo Hamburgo, RS, Brasil.
}

$\diamond$

\begin{abstract}
RESUMO
Este artigo trata de uma discussão teórica que aborda a dimensão educativa de práticas de educação não escolar, especialmente aquelas desenvolvidas em programas e projetos socioeducativos. Partindo do reconhecimento que tais práticas têm sua dimensão pedagógica e seus modos de saber fazer relativamente conhecidos, envida esforços no sentido de teorizar sobre o campo, admitindo, a priori, a existência de uma dimensão especificamente educativa da educação não escolar, tomando como referência as postulações teóricas de Boavida e Amado (2006). O texto encerra apresentando argumentos cuja elaboração original pretende trazer novos elementos ao debate no âmbito das teorias educacionais, contribuindo para o avanço do conhecimento científico.
\end{abstract}

Palavras-chave: Educação. Educação não escolar. Socioeducativos. Dimensão educativa. Dimensão pedagógica.

\begin{abstract}
This article deals with a theoretical discussion that addresses the educational dimension of non - school education practices, especially those developed in socio - educational programs and projects. Based on the recognition that such practices have their pedagogical dimension and their expertise virtually known, it endeavors to theorize about the field, admitting, a priori, the existence of a specifically educational dimension of non-school education. The reference is the theoretical postulations of Boavida and Amado (2006). The text is conclued by presenting arguments whose original elaboration intends to bring new elements to the debate in the scope of educational theories, contributing to the advance of scientific knowledge.
\end{abstract}

Keywords: Education. Non-school education. Socio-educational. Educational dimension. Pedagogical dimension.

\section{RESUMEN}

Se trata de um artículo de discusión teórica que aborda la dimensión educativa de prácticas de educación no escolar, especialmente aquellas desarrolladas en programas y proyectos socioeducativos. A partir del reconocimiento que tales prácticas tienen su dimensión pedagógica y sus modos de saber hacer relativamente conocidos, se esfuerzan en teorizar sobre el campo, admitiendo a priori la existencia de una dimensión específicamente educativa de la educación no escolar, tomando como referencia las postulaciones teóricas de Boavida y Amado (2006). El texto encierra presentando argumentos cuya elaboración original pretende traer nuevos elementos al debate en el ámbito de las teorías educativas, contribuyendo al avance del conocimiento científico.

Palabras clave: Educación. Educación no escolar. Socioeducativos. Dimensión educativa. Dimensión pedagógica. 


\section{INTRODUÇÃO}

No sul do Brasil, no último decênio, um grupo de pesquisadores vem estudando o campo da educação não escolar ${ }^{1}$. Resguardadas as diferenças entre os estudos, em especial, quanto às divergências sobre os modos de nomeação de tais prática, os resultados de pesquisas têm demonstrado esforços no sentido de ressaltar a dimensão educativa presente na educação não escolar. Contudo, os esforços de teorização deste campo implicam em reconhecer que toda a prática educativa tem em si um conjunto de componentes teórico/prático que se agregam, complementam e se traduzem em duas dimensões: uma pedagógica e outra educativa.

É com base no estudo dos pesquisadores portugueses Boavida e Amado (2006) que, neste artigo, buscaremos discutir a especificidade do educativo no campo da educação não escolar o que nos exige e nos impele um estudo de base teórica que é, ao mesmo tempo, resultado das pesquisa que já estamos desenvolvendo e um esforço em contribuir para as teorias da Educação. Vale ressaltar que fazemos aqui, a partir dos referidos autores, uma distinção entre as dimensões pedagógica e educativa, a fim de que se possa produzir a presente problematização.

Boavida e Amado (2006, p. 44) partem da afirmação de que:

[...] há em todas as inúmeras situações educativas, em que a prática se concretiza, e em todas as abordagens que pressupõem a teoria, um residual comum a todas as situações educativas suscetíveis de ser teorizado, que diz respeito à natureza do educativo em si mesmo.

Para nós, contudo, tal afirmação converte-se na questão norteadora das argumentações apresentadas neste texto. Reconhecemos a existência, a priori, do especificamente educativo da educação escolar. Mas por que dizermos isto? Para afiançar que o exercício aqui realizado não pretendeu dissociar o conceito maior, qual seja, a educação. Outrossim, Palhares (s.d) referindo-se ao cenário educativo de Portugal, aponta para volumosos estudos que emergem das práticas de educação não escolar evidenciando uma forte erosão sofrida pela educação escolar que, segundo o autor, vem perdendo sentido ao longo dos anos. Reconhecendo intencionalidades, objetivos e especificidades pedagógicas distintas, compreendemos ser importante refletir sobre o que denota a existência e a concomitância de práticas educativas, escolares e não escolares.

\footnotetext{
1 SANTOS (2015), ZUCCHETTI; MOURA (2010, 2014, 2016), LEMES (2017), RUBINI; SANTOS (2016), SANTOS; LEMES (2016), LOCKMANN $(2013,2016)$. Artigos recentes desses autores também estão compilados no dossiê Práticas de educação não escolar e não forma, na Revista Série-Estudos. v. 21, n. 43, set./dez. 2016, organizado por ZUCCHETI, MOURA e GROPPO.
}

Assim sendo, se parte da afirmação de que projetos socioeducativos "são práticas de educação não escolar cujas ações de promoção da cidadania e de proteção social, voltadas às crianças e jovens socialmente vulnerabilizados, evidenciam a base compensatória de tais programas/projetos" (ZUCCHETTI; MOURA; MENESES, 2014, p. 970). A partir de nossas pesquisas, desenvolvidas desde 2006 em uma cidade da região metropolitana de Porto Alegre/RS, observamos que, de modo geral, os sujeitos alvo dos projetos socioeducativos são, principalmente, crianças e adolescentes pobres do ponto de vista socioeconômico, alunos de escolas públicas e filhos de trabalhadores, especialmente, da produção e transformação do setor secundário da economia e/ou desempregados, moradores das periferias das cidades. Em alguns casos, são trabalhadores infantis, vítimas de violência e/ou cumprem medidas judiciais, dada a sua condição de autores de atos infracionais.

Os projetos educativos têm tradição histórica no campo da assistência social, entretanto, mais recentemente, a partir da Lei de Diretrizes e Bases ${ }^{2}$ (LDB) passaram a ser reconhecidas como sendo educativas e complementares à educação escolar. Formalizadas em um sistema paralelo ao sistema escolar, qual seja, o campo da assistência social vem permitindo, no mínimo, problematizar sua vertente meramente assistencialista, bem como a sua propalada dinâmica não formal, além de permitir identificar a importância da intersetorialidade de políticas sociais.

Devemos aqui destacar o avanço que a emergência desse tipo de práticas representa. Vale lembrar que, anterior à universalização da escola pública, contingentes de filhos de trabalhadores eram mantidos fora da instituição escolar, alguns deles frequentando projetos assistenciais/ assistencialistas com vistas a uma socialização provisória, de reposição, no sentido compensatório, mas tida como indispensável para o acesso e a permanência no sistema oficial de ensino e seus modos de socialização escolar. Tais intervenções, realizadas preferentemente por prefeituras municipais e associações locais da sociedade civil, centravam suas estratégias educativas no campo da formação para o trabalho voltadas, tanto à prevenção a marginalidade (em tempos em que marginalidade e pobreza eram considerados conceitualmente sinônimos) na perspectiva da ocupação do tempo livre, quanto à formação do futuro trabalhador fabril. Desde a modalidade de oficinas, as estratégias de ensino iam direcionadas na perspectiva de aprender a fazer, mais especialmente em aprender a ser.

É, no entanto, a partir do Estatuto da Criança e do Adolescente $^{3}$ (ECA, 1990) - antes da própria LDB -

\footnotetext{
BRASIL. Lei no 9.394. Estabelece as Diretrizes e Bases da Educação Nacional (LDBN), de 20 de dezembro de 1996. Brasília, DF.

3 BRASIL. Lei no 8.069. Estatuto da Criança e do Adolescente (ECA), de 13 de julho de 1990. Brasília, DF.
} 
que são criadas as condições necessárias para agregar o qualificativo educativo a tais práticas, até então, caracterizadas como essencialmente assistenciais e/ou assistencialistas; cuja forma origina o que nomeamos, genericamente, como programas e/ou projetos socioeducativos. A partir de então, alinhadas ao entendimento de que se trata de práticas de proteção social básica, no âmbito de um conjunto de resoluções e regulações que compreende a família como núcleo central da política social, que mantém forte relação com a Lei Orgânica da Assistência Social ${ }^{4}$ (LOAS) e com o Sistema Único da Assistência Social (SUAS).

Soma-se a este contexto sócio-histórico a emergência e a consolidação de mais um ente voltado à oferta de tais ações que, de modo geral, buscam instaurar outras formas de governo de tais segmentos da população: o terceiro setor como proponente e/ou parceiro do setor governamental. Entre estes, mais recentemente, a (pre)ocupação com a inclusão social dos piores situados instaurando ações cujas práticas pedagógicas recaem mais sobre o acesso à cultura e aos bens culturais enquanto estratégias associadas a então tradicional formação para e pelo trabalho de jovens adolescentes (ZUCCHETTI; MOURA; MENESES, 2014).

Assim sendo, é possível afirmar que epistemologicamente são duas as modalidades conhecidas de práticas socioeducativas experienciadas no Brasil considerando-se, especialmente, os sujeitos crianças e adolescentes vulnerabilizados socialmente. Uma primeira que se assentou na doutrina da situação irregular, cuja ênfase recai na vitimização de crianças e adolescentes, tendo o recurso da institucionalização como medida preferencial e que, pelo menos, do ponto de vista legal, desapareceu com a extinção do Código de Menores. que vigorou de 1979 a 1989. Outra que, sob os auspícios da doutrina da proteção integral, exprime um esforço jurídico-pedagógico necessário para instaurar um novo modo pelo qual a sociedade brasileira passou a tratar a infância e a adolescência pobre que emergiu com o ECA.

Feita esta introdução seguimos, a partir de estudos que tomam por base a revisão da literatura sobre o tema, cotejando com os argumentos de Boavida e Amado (2006), buscando discutir e apontar o que podemos considerar como o especificamente educativo, o educativo em si, de tais práticas.

\section{A dimensão PEDAgógica doS SOCIOEDUCATIVOS}

Afirmamos anteriormente, no que diz respeito às práticas de educação não escolar e, especificamente,

\footnotetext{
4 BRASIL, Lei no 8.742. Lei Orgânica da Assistência Social (LOAS), de 7 de dezembro de 1993. Brasília: DF.
}

aos socioeducativos, que sua dimensão pedagógica está relativamente conhecida. Ou seja, aquilo que lhe constitui pelo concreto, no sentido da ação, no âmbito do método, que revela fortes potencialidades práticas do ponto de vista acadêmico, está suficientemente estudado. Esforços de pesquisadores, especialmente a partir dos anos 2000, vêm encontrando condições acadêmicas que, ao reconhecer ações socioeducativas como práticas de educação, permitiram que sobre essas fossem produzidas importante investigações. Resultados de trabalhos de conclusão de curso nas áreas de licenciaturas, dissertações, teses e o fortalecimento de linhas de pesquisa, no âmbito de algumas universidades do sul do Brasil ${ }^{5}$, têm feito crescer o interesse sobre as práticas educativas no campo social a partir de diferentes problemáticas. Constatação que, nos últimos anos, contribuíram para suprir as carências de estudos nesta área do conhecimento e, a que tudo parece, na sua grande maioria, se ocupam em evidenciar o que se faz em tais práticas ${ }^{6}$.

As investigações, em geral, sinalizam para a presença de um fazer que considera a ação educativa direcionada para um certo tipo de sujeito. Trata-se dos mesmos que frequentam as escolas e que transitam em um duplo espaço de formação. Têm o ingresso e a permanência nos espaços socioeducativos dado, entre outros, por estarem subjugados à violência e aos maus tratos, expostos à pobreza socioeconômica, ao trabalho infantil, muitas vezes tendo fragilidade nos vínculos familiar e escolar e demandando cuidado no contraturno da escola. Constituem-se estas também as situações que mais geram encaminhamentos por parte das instituições de proteção da infância e da adolescência ou a busca ativa por parte de familiares. Realidades estas que concretizam uma ação intencional baseada em um modo certo de pensá-los, a fim de atendê-los, assisti-los e deles cuidar, mantendo-os fixados em um processo de inclusão precarizada ${ }^{7}$.

Enquanto modo preferencial de saber fazer, as práticas pedagógicas dos socioeducativos têm na modalidade de oficinas sua estratégia preferencial. É nessa operacionalidade que a manualidade e a espontaneidade sobressaem mediante práticas prescritivas: quer pela ausência de uma estrutura fortemente formalizada e didaticamente descrita; quer por uma orientação pedagógica centralizada e produtora de um modelo de gestão que determina, não somente, os modos de ensinar, mas certa tendência à sua verticalização, modelo hegemônico na prática escolar. Manualidade

\footnotetext{
5 Nos referimos às Universidades Feevale, Unisinos e UFRGS.

6 Seguimos nesta seção procurando demonstrar o que até aqui afirmamos. Obviamente, chamando a atenção para o fato de que este exercício não é tomado como absoluto. Pode, porém, presumir certo consenso.

7 Exemplo disto pode ser observado nas práticas assistenciais em tempos do Código de Menores e suas estratégias de atenção à situação irregular, cujas ações resultaram, geralmente, em práticas segregacionistas.
} 
e espontaneidade que, também, em detrimento de um conhecimento acadêmico prévio, intelectualizado mesmo que muitas vezes existente -, tende a favorecer a emergência de saberes das comunidades onde estão inseridos tais projetos. Não estamos diante desta afirmação reconhecendo o laissez faire da prática pedagógica dos socioeducativos, ao contrário, tais empreendimentos pedagógicos denotam na espontaneidade um forte mote, uma força motriz, cuja orientação tende ao cuidado do outro, na perspectiva do cuidado do ser no mundo, tal qual atribuída por Boff (1999).

Outro aspecto que merece destaque, em estreita relação com o exposto acima, diz respeito aos sujeitos envolvidos, os quais para além da identificação a priori, nos conduzem identificar quem são os educadores que atuam neste campo. Recrutados, preferentemente, no interior dos cursos de licenciaturas das universidades tais estudantes se associam a outros, cuja formação é eminentemente técnica. Esses são os oficineiros que atuam nas artes visuais, teatro, esportes, música, entre outros, quase sempre seu campo de atuação profissional. Em conjunto, constituindo uma unidade na diversidade, emergem os educadores sociais reconhecidos como o profissional que atua nos socioeducativos ${ }^{8}$.

Nessas práticas há uma intencionalidade, quase que generalizada, para buscar construir uma ação educativa que se diferencie da educação escolar no sentido atribuído às aprendizagens curriculares, às metodologias baseadas em tempos previamente definidos e avaliações de aproveitamento, seguindo-se o argumento da ineficácia de uma educação bancária nos moldes como foi criticada por Freire (1992).

Nesse sentido, uma certa desordem (BALANDIER, 1997) no cotidiano do trabalho são expressão de um planejamento pedagógico sempre aberto a alterações, porque colado na vida das crianças e adolescentes. Nele não há marcadores de início, meio e fim. O ingresso dos que vem chegando é sempre o ponto de começo e de recomeço para todos.

Não obstante, devemos assinalar que a crescente ênfase pedagógica conferida a tais práticas parece estar

\footnotetext{
8 Depois da vários anos tramitando na Câmara e no Senado a profissão do educador social foi objeto da Comissão de Legislação Participativa (CLP) quando foi realizada em $8 \mathrm{dez} .2016$ uma audiência pública para discutir a regulamentação da profissão de educador social - Projeto de Lei 4.353. Abrindo o evento, o presidente da CLP, Chico Lopes (PCdoB/CE), alertou que "mesmo sem regulamentação, a educação social consta na classificação brasileira de ocupações do Ministério do Trabalho e muitos estados já abriram concursos públicos exclusivo para a contratação desses profissionais. Disponível em: http://www2.camara. leg.br/atividade-legislativa/comissoes/comissoes-permanentes/clp/ noticias/audiencia-publica-debateu-a-regulamentacao-da-profissao-deeducador-social. Acesso em: 4 jan. 2017. Atualmente o referido projeto de lei (PLS 328/2015) tramita na Comissão de Assuntos Sociais (CAS) do Senado Federal. Disponível em: www12.senado.leg.br. Acesso em: 2 maio 2017.
}

relacionada à naturalização da desigualdade e seus processos de inclusão ao longo dos anos.

\section{A Dimensão Visível do SOCIOEDUCATIVO: QUANDO ANTES E DEPOIS SE FUNDEM}

É a partir do exposto por Boavida e Amado (2006) que buscamos compreender o que caracteriza a dimensão educativa do socioeducativo. Para tanto, partimos de três perguntas que, segundo os autores, permitem traçar os esforços empreendidos para que seja possível identificar como nos desenvolvemos e nos tornamos sujeitos dessas práticas de educação: onde é visível o especificamente educativo? Em que este consiste? E de que forma tende a se manifestar?

Para Boavida e Amado (op. cit.) aquilo que caracteriza o educativo é expresso sempre a posteriori, emergindo, por assim dizer, no residual de todas as práticas educativas. O que se repete é o que identifica e, portanto, lhe atribui consistência. Manifesta-se em tudo o que se faz capaz de compreender e reconhecer como sendo a sua capacidade de educar. Traduz-se, segundo os autores, na combinação da existência de um antes, um durante e um depois do que denominam de ato educativo. Contudo, embora difíceis de definir, geralmente são fáceis de reconhecer, mas compreendemos que não se esgotam no seu conjunto.

No caso da educação não escolar, realizando um paralelo aos estudos de Boavida e Amado (2006), preliminarmente, podemos reconhecer a existência de um antes, um durante e um depois. Contudo, entendemos que essa combinação resulta tão difícil de definir quanto de sustentar, posto que para nós, aquilo que caracteriza o educativo nem sempre se expressa a posteriori. Pelo contrário, no que se refere às práticas de educação não escolar entendemos que o especificamente educativo, possui consistência e forma de se manifestar que não, necessariamente, se torna visível como um produto acabado, seja como saberes, habilidades, competências ou como um sujeito específico. Assim, propomos discutir o especificamente educativo do socioeducativo tomando, apenas como referência a combinação do antes, durante e depois (BOAVIDA; AMADO, 2006).

Desse modo, consideramos um antes - aquilo que precede a tudo - os sentidos que são atribuídos ao social nesta modalidade de atenção aos piores situados social e economicamente. Dessa perspectiva, o antes constitui o cenário macrossocial no qual emerge e se manifesta o processo de inclusão/inserção dessas crianças e jovens, geralmente pela via da precarização, dada sua origem socioeconômica.

$\mathrm{O}$ que consensuamos denominar de social assume sentidos diversos quando buscamos compreender o conceito a partir de pressupostos modernos e/ou 
contemporâneos. Na modernidade, o social remete de imediato à esfera do trabalho, ou melhor, à sociedade do trabalho, desde onde é produzida a possibilidade de leituras como a da sociedade orgânica, defendida por Durkheim (2010) ou a do conflito de classes, a partir de Marx e Engels (1999). No contemporâneo, de metáfora da sociedade o social se converte em jogos de linguagem. Neste sentido, afirma Rouanet:

A sociedade é uma monstruosa rede constituída pela imbricação de várias classes de enunciados: denotativos, que descrevem fatos ou acontecimentos; prescritivos que formulam normas e procedimentos; imperativos que traduzem ordens ou instruções (1987, p. 234).

Segue o autor declarando que tais enunciados, heteromórficos entre si, tornam impossível disciplinar a todos do mesmo modo. Nese sentido, a heterogeneidade enunciativa permite recuperar a complexidade que vem sendo atribuída ao conceito, especialmente, no que tange a sua representação. O social, em geral, é utilizado para designar parcela da sociedade do mesmo modo que a designação povo também não representa o conjunto de cidadãos de uma nação, mas uma parte dela, em geral, a menos letrada, menos abastada, menos educada. Social e povo, neste sentido, ganham contornos muitos semelhantes, porém, com matizes bem diversos ao longo da nossa curta experiência de sociedade democrática.

No que tange, por exemplo, aos socioeducativos chamados na sua origem de extraclasses tinham, à época, orientação meramente assistencialista ditada pelo extinto Código de Menores. Por meio de práticas higienistas na prevenção à marginalidade eram oferecidos a partir de normativas da Legião Brasileira de Assistência (LBA). Nesse sentido, o social assumia forte caráter de exclusão e segregação aos piores situados.

No entremeio de tais práticas, intervenções sociais fomentaram a centralidade do trabalho na modalidade de formação inicial. Intervenções que vieram sustentar um tempo de moratória necessário para aplacar os altos índices de trabalho infantil persistentes até hoje. Mediante o crescente repudio internacional da exploração da mão de obra de crianças e adolescentes utilizada na consolidação do capitalismo brasileiro, o social passou a ser objeto de intervenção cuja ênfase recai sobre uma socialização de reposição, por meio do governo de si. Nesse contexto, o Estado associa-se a organismos não governamentais e ao chamado terceiro setor que, em conjunto, passam a assistir aos desfavorecidos.

Não menos importante é evidenciar a presença de uma aporia fundamental nesse contexto que nos induz a pensar a existência de um depois neste antes. Um agora, talvez, onde o social, após a emergência do Estatuto da Criança e do Adolescente, passa a assumir valor de direito humano em sua dimensão de cuidado. Um cuidado voltado à criança e ao adolescente em peculiar situação de desenvolvimento, mas, também, porque na iminência do chamado risco social, coloca toda a sociedade em risco.

Em síntese, no âmbito da educação não escolar o antes da educação constitui uma dimensão macrossocial que ocupa um espaço de interseção com o propriamente pedagógico, posto que além de evidenciar intencionalidades visa, ainda que de forma difusa, a algum tipo de uniformidade. Em geral, o antes da educação não escolar consiste em uma espécie de aposta profética que incide na vida desses sujeitos forçando a confirmação de seu triste destino como 'desfavorecido', cumprindo o ciclo de um percurso desde sempre traçado.

Trata-se de um processo complexo que esconde toda a perversidade dos jogos de poder. O complexo aqui diz respeito ao estreitamento do ponto de vazão de qualquer potencial possível de ser explorado no âmbito das práticas do socioeducativo. Na medida em que o antes se expressa na forma de vaticínios, estreitando o ponto de vazão do inédito, o depois se enrijece na forma do sempre igual e se lança sobre jovens como um destino inexorável. Nesse processo, antes e depois se contraem, pulam a fase do durante e produzem o que a repetição, o que o identifica, o que se manifesta como aquilo que se compreende e se reconhece como educar.

Nesse sentido, o antes e o depois se manifestam e se tornam visíveis como as duas faces de uma prática de educação que assume caráter de controle social dos piores situados e que visa a disciplinarização de crianças, jovens e adolescentes pobres a partir da oferta de mais tempo em atividades educativas.

\section{A DIMENSÃo EDUCATIVA DO SOCIOEDUCATIVO: OS INTERSTÍCIOS ENTRE AFETO E CORPO}

Retomando nossa concepção de projetos socioeducativos já apresentada anteriormente, convém ressaltar que nos alinhamos com Brandão (2012) naquilo que o autor concebe como socioeducativo. Para o referido autor, tratam-se de modalidades de práticas que se caracterizam como tempos de dignidade para a infância-adolescência populares. Referência realizada em relação à dimensão socioeducativa do Programa Mais Educação que em nada

confunde-se com uma pedagogização da vida, ou uma espécie de expansão impositiva da cultura escolar, a outros redutos do cotidiano. Antes pelo contrário, trata-se de, em primeiro lugar, libertar a própria educação de seu pedagogismo utilitário que, ele sim, aprisiona a cada dia mais a própria escola entre momentos de um ensino centrado em uma progressiva árida funcionalidade (BRANDÃO, 2012, p. 69). 
Novamente, fazendo um paralelo aos estudos de Boavida e Amado (2006), queremos realçar o durante como o elemento chave para discutirmos o especificamente educativo do socioeducativo.

Entendemos que o durante constitui uma dimensão de complexidade, posto que se oferece como virtualidade para aquilo que pode vir a ocorrer no encontro com o inédito da vida. Trata-se de uma dimensão marcada pela perspectiva de uma estética da professoralidade, na qual, segundo Pereira (2013), emerge singularidades, trajetórias pessoais, memórias, presença dos pares, resistências, transformações e diferenciações de si. No caso dos educadores sociais, a busca pela diferenciação assume um vigor especial quando se trata de estabelecer distinções entre o fazer profissional no âmbito da educação escolar e o fazer da prática que se concretiza no âmbito da educação não escolar.

Nesse sentido, defendemos que o durante diz respeito ao exercício de uma ação de interferência que se exerce sobre um si, abrindo-se para o amplo espectro de diferentes formas de sensibilidade, em um exercício que se alimenta de uma relação possível entre sujeitos educadoreducando, baseada em uma relação de horizontalidade. Trata-se de um processo interativo, dialógico entre sujeitos que estão em processo de (trans)formação pela aprendizagem de si e dos outros no mundo. $\mathrm{O}$ durante configura a dimensão de uma intencionalidade que se consubstancia pelo e no encontro, na relação educadoreducando. $\mathrm{O}$ durante constitui, portanto, a própria dimensão educativa, isto é, aquilo que é possível emergir de tais práticas.

Definido como a própria dimensão educativa, no durante, os lugares de poder-saber (educador-educando) se fundem para instaurar o modo de ser parceirosaprendentes. Nesse espaço não há um professor que acredita que somente seus conhecimentos são verdadeiros, um professor que olha para seu aluno (seja criança, adolescente ou jovem) como se este não carregasse saberes e conhecimentos. Nesse espaço do socioeducativo, há exercício de cumplicidade, há exercício de (de)formação, ação intencional de retirada da forma instituída para instituir outras e novas formas de ser aprendente.

A dimensão educativa do socioeducativo constitui um ato cuja natureza é a própria desnaturalização dos instituídos; ato educativo cujo exercício de desconstrução dos a priori implica, ao mesmo tempo, dois movimentos combinados. Por um lado, uma ação cuidadosa que evita cair nas práticas do instituído, aqui entendido como o modelo escolar. Por outro, uma ação vigorosa que busca instaurar novidades inusitadas. Trata-se de um ato que busca instaurar o "inédito viável" de Freire (1992, p. 206-207):
O inédito viável é na realidade uma coisa inédita, ainda não conhecida e vivida, mas sonhada e quando se torna um percebido destacado pelos que pensam utopicamente, esses sabem, então, que o problema não é mais um sonho, que ele pode se tornar realidade. Assim, quando os seres humanos conscientes querem, refletem e agem para derrubar as situações limites que os e as deixaram a si e a, quase todos e todas limitados a ser menos, o inédito viável não é mais ele mesmo, mas a concretização dele no que ele tinha antes de inviável. Portanto, na realidade são essas barreiras, essas situações-limites que mesmo não impedindo, depois de percebidos-destacados, a alguns e algumas de sonhar o sonho, vêm proibindo à maioria a realização da humanização e a concretização do ser mais.

Discutir o durante como dimensão educativa das práticas de educação não escolar implica explicitar os matizes teóricos que lhes dão sustentação e não apenas reconhecer nossas heranças, como por exemplo, o pensamento freireano. Empreender essa tarefa demanda o esforço de buscar articular tal vertente com postulações diversas a fim de promovermos o adensamento da discussão.

Nesse sentido, seguindo as pistas oferecidas por Bondía (2002, p.20) propomos pensar a dimensão estritamente educativa do socioeducativo a partir do par experiência/sentido como um processo que implica forjar o pensamento para além do raciocínio. Trata-se de conceber a dimensão educativa como exercício de abertura que aponta para um plano de produção tanto de conhecimento quanto da própria realidade conhecida. Um exercício de abertura que se ancora em uma cognição inventiva que não aceita a representação de um mundo supostamente dado. Ao contrário, a dimensão educativa do socioeducativo investe na tarefa de criar mundos inexistentes, porém, possíveis.

A dimensão educativa da educação não escolar, portanto, constitui o pensar que não se resume ao raciocinar, é o pensamento intrusivo que confere sentido ao que somos e ao que nos acontece colado na materialidade radical da vida. Trata-se da experiência que nos insta a criar palavras e/ou outras formas expressivas para enunciar o pensamento que, incessantemente, brota do assédio da vida nos tomando de assalto, de forma inevitavelmente imprevisível. A dimensão educativa, enfim, é a própria experiência e "a experiência é o que nos passa, o que nos acontece, o que nos toca. Não o que se passa, não o que acontece, ou o que toca" (BONDÍA, 2002, p. 21).

Muitas são as coisas que passam em nossa vida, no entanto, muito pouco ou quase nada vivemos como experiência, porque a experiência implica acessar uma dimensão da vida que está prenhe de forças indiscerníveis. Somente nesse sentido, podemos admitir um durante da 
educação não escolar, uma dimensão especificamente educativa que (trans)forma educador-educando em forma fluída cujo contorno apenas (trans)figura encontros entre afeto e corpo. Admitimos a dimensão educativa da educação não escolar como o tempo da duração de um espaço infinitesimal no qual educador-educando se fundam, pelo acesso/produção do plano de forças que cria/transforma a experiência.

Ao substituirmos o durante por tempo de duração para falarmos daquilo que se manifesta como especificamente educativo, nas práticas da educação não escolar, queremos dar destaque a processualidade da imbricação mundoafetabilidade-corporificação. Queremos apontar o efeito da abertura atenta do corpo ao plano coletivo de forças, um processo que, mais do que promover engajamentos e interferir na condição de atores/protagonistas, produz elaborações coletivas marcadas pela intensidade de cores, pela poesia de histórias, pela fragilidade da palavra e pela intensidade dos afetos, o que caracteriza a produção de novas realidades.

É nesse ponto exato e fugaz de entrecruzamento mundo e afetabilidade que corpos tomam forma compondo um caleidoscópio de saberes e fazeres, sempre precário, prestes a oscilar na direção de outras imagens. Somente desde este ponto é que a vida se abre de forma ampla e extensa como possibilidade de nos forjarmos diferenças de nós mesmos. Um processo cujos resultados são tão imprevisíveis quanto precários, um processo que nunca coagula em tempos extensos (antes, durante e depois) já que é fluxo incessantemente produtor de novos e inéditos pontos de abertura a outras diferenciações. Assim, a dimensão educativa das práticas de educação não escolar é experiência que instaura mundo e sujeitos em um processo de coengendramento, um processo que ocorre nos interstícios da vida instituída. Processo que abre, afeta, anima, faz corpo e força a pensar o inédito, o imprevisível, o impensável.

Evidentemente, ao postularmos a dimensão educativa como experiência, o depois somente toma sentido como devir. Concebemos o depois como devir, como aquilo que escorre como virtualidade e que pode fazer surgir uma novidade. Entendemos que o depois constitui o incessante esforço de estabilidade em um mundo feito de puro fluxo e vertigens. Assim, que o depois não existe como produto acabado, posto que se apresenta como potencialidade cambiante, plural e em constante processo de produção.

Diferentemente, da educação escolar que verifica todos os saberes, conteúdos, na perspectiva de uma educação bancaria tal qual definida por Freire (1982), até onde conhecemos, na educação não escolar, não há ferramentas capazes de alcançar a processualidade. $\mathrm{O}$ depois constitui, portanto, uma relação que poderá ou não acontecer, uma relação que não é técnica e nem bancária e que resulta difícil antecipar. Neste sentido, também, nos diferenciamos de Boavida e Amado (2006).

\section{CONSIDERAÇÕES FINAIS}

Ao longo do texto procuramos desenvolver nossos argumentos cotejando as elaborações teóricas de Boavida e Amado (2006). Longe de desconsiderarmos a relevância e a pertinência de suas postulações, buscamos tomá-las como estímulo para problematizar, particularmente, a dimensão estritamente educativa das práticas de educação não escolar. Reconhecendo a necessidade de ampliar as bases teóricas na direção de uma teoria da educação não escolar e, no presente texto, procuramos partir das três perguntas que, segundo os autores, permitem apontar onde é visível o especificamente educativo? Em que este consiste? E de que forma tende a se manifestar?

Convém, no entanto, lembrar que, conforme afirmam os autores:

nem todas as situações dadas à partida como educativas, ou pensadas e previstas como tal, o vêm a ser efetivamente, enquanto outras, que não eram para o ser, se transformam nisso, ou ainda, só foram educativas para certas pessoas e em certos momentos [...] (BOAVIDA; AMADO, 2006, p. 46).

Tal argumento reafirma a ideia de que ao largo de toda a diversidade presente no campo da educação é ela [a própria diversidade] que nos permite ver emergir - mesmo que de maneira difusa - o que é comum e, enquanto tal, se manter constante em todas as situações e manifestações. Com isso poderíamos, talvez, responder em parte a primeira questão afirmando a diversidade como característica especificamente educativa dos socioeducativos. Tal entendimento nos remete a reafirmar duas importantes considerações: primeiro, que os socioeducativos não perderam, mesmo nas suas versões pós-ECA, o forte caráter de controle social dos piores situados socialmente e que, mesmo em abordagens diferenciadas e específicas, buscam a fim e a cabo, teleologicamente falando, promover maior disciplinarização a partir da oferta de mais tempo em atividades educativas. Daí também ser possível pensar que a crescente ênfase no pedagógico de tais práticas educativas resulta da crescente naturalização da desigualdade e seus processos de inclusão ao longo dos anos.

Não obstante, a busca por respostas às questões sobre em que consiste, como e onde se manifesta o especificamente educativo, fica subsumida em uma plêiade de elementos que evidenciam mais a dispersão, em detrimento daquilo que é comum e constante nas práticas de educação não escolar. Evidentemente, tratase de questões que merecem ser investigadas por meio de 
um olhar atento sobre este educativo difuso. As futuras pesquisas, particularmente, deverão perguntar às crianças e aos jovens adolescentes que frequentam práticas socioeducativas o que e como se aprende nestes espaços/ tempos de viver.

Contudo, no presente texto, tentamos ainda que de forma inicial apresentar alguns apontamentos obtidos a partir dos estudos que vimos desenvolvendo e que nos autorizam e esboçar algumas alternativas de resposta às questões colocadas por Boavida e Amado (2006). Nesse sentido, concordamos com as elaborações teóricas dos referidos pesquisadores, em parte, quando admitimos a ideia de uma temporalidade que se coloca à priori. Um tempo anterior a própria prática que determina as condições por meio das quais os protagonistas deverão se movimentar, conduzindo, via de regra à confirmação das expectativas sociais. Contudo, a partir desse ponto começamos a nos afastar das elaborações de Boavida e Amado (2006), cotejando seus argumentos.

Nossa diferenciação começa na própria ideia de um antes que, segundo os autores, embora seja parte de um conjunto, possui margem de discernibilidade. $\mathrm{Na}$ medida em que situamos o antes como os sentidos que são atribuídos ao social, entendemos que nesta modalidade educativa, voltada aos piores situados, social e economicamente, antes e depois constituem as duas faces da mesma moeda. Ou seja, o que resultará da ação educativa está determinado na sua concepção e se processa no próprio ato educativo. Esta é a visibilidade molar da dimensão educativa das práticas de educação não escolar: o cumprimento de profecias auto realizadoras que insistem em afirmar a incompetência de sujeitos oriundos de condições de vida social e economicamente desfavorecidas.

Assim, atravessando a molaridade do campo social, situamos a dimensão educativa do socioeducativo na processualidade da experiência, no plano comum das forças do mundo, na experiência compartilhada que, operando por meio do aumento da potência de agir, instaura mundos, sensibilidades, corpos, sujeitos, saberes e fazeres. Nesse sentido, o socioeducativo implica uma dimensão cujo acesso pressupõe uma política cognitiva criadora.

\section{REFERÊNCIAS}

BALANDIER, G. A desordem. São Paulo: Bertrand Brasil, 1997.

BOAVIDA, J.; AMADO, J. A especificidade do educativo: seu potencial teórico prático. Revista Portuguesa de Pedagogia, Coimbra, v. 40, n. 1, p. 43-61 2006.

BOFF, L. Saber cuidar: ética do humano - compaixão pela terra. Petrópolis: Vozes, 1999.
BONDÍA, J. L. Notas sobre a experiência e o saber da experiência. Revista Brasileira de Educação, Rio de Janeiro, n. 19, p. 20-28, jan./abr. 2002. Disponível em: http://www. scielo.br/pdf/rbedu/n19/n19a02.pdf. Acesso em: set. 2016.

BRANDÃO, C. R. O outro ao meu lado: algumas ideias de tempos remotos e atuais para pensar a partilha do saber e a educação de hoje. In: MOLL, Jaqueline et al. Caminhos da Educação Integral no Brasil: direito a outros tempos e espaços educativos. Porto Alegre: Penso, 2012. p. 46-71.

DURKHEIM, E. Da divisão do trabalho social. São Paulo: Martins Fontes, 2010

FREIRE, P. Pedagogia do oprimido. 11. ed. Rio de Janeiro: Paz e Terra, 1982.

FREIRE, P. Pedagogia da Esperança: Um Reencontro com a Pedagogia do Oprimido. Rio de Janeiro: Paz e Terra, 1992.

LEMES, M. A. Estratégias de participação na política de assistência social na perspectiva de Paulo Freire. 2017. Tese (Doutorado em Educação) - Programa de Pós-Graduação em Educação, Universidade do Vale do Rio dos Sinos, São Leopoldo, 2017.

LOCKMANN, K. A proliferação das Políticas de Assistência Social na educação escolarizada: estratégias da governamentalidade neoliberal. 2013. Tese (Doutorado em Educação) - Programa de Pós-Graduação em Educação, UFRGS, Porto Alegre, 2013. Disponível em: http://www. lume.ufrgs.br/handle/10183/79669. Acesso em: 2 maio 2017.

MARX, K.; ENGELS, F. Manifesto Comunista. Versão para e-book, 1999. Disponível em: http://www.ebooksbrasil. org/adobeebook/manifestocomunista.pdf. Acesso em 27 abr. 2017

PALHARES, J. A. Quarenta anos na sombra da crise da escola: possibilidades e contrariedades no percurso da educação não-escolar. Inédito. Disponível em: http:// repositorium.sdum.uminho.pt/handle/1822/10099.

Acesso em: 2 maio 2017

PEREIRA, M. V. Estética da Professoralidade: um estudo crítico sobre a formação do professor. Santa Maria: UFSM, 2013.

SANTOS, K.; LEMES, M. A. O sentido do trabalho educativo no campo social. Série-Estudos: Periódico do Programa de Pós-Graduação em Educação da UCDB, [S. l.], p. 45-67, set. 2016. ISSN 2318-1982. Disponível em: http://www.serieestudos.ucdb.br/index.php/serie-estudos/article/view/912. Acesso em: 2 maio 2017.

ROUANET, S. P. As razões do Iluminismo. São Paulo: Companhia da Letras, 1987.

RUBINI, L. R.; SANTOS, N. I. S. Proteção, prevenção e convívio: analisando práticas com educadores sociais. Série-Estudos: Periódico do Programa de Pós-Graduação em Educação da UCDB, [S. l.], p. 69-88, set. 2016. ISSN 23181982. Disponível em: http://www.serie-estudos.ucdb.br/index. php/serie-estudos/article/view/910. Acesso em: 2 maio 2017. 
SANTOS, K. Intencionalidades em conflito: um estudo das práticas educativas de ONGs. 2015. Tese (Doutorado em Educação) - Programa de Pós-Graduação em Educação, Universidade do Vale do Rio dos Sinos, São Leopoldo, 2015. Disponível em: http://www.repositorio.jesuita.org.br/handle/ UNISINOS/5775. Acesso em: 2 maio 2017.

ZUCCHETTI, D. T.; MOURA, E. P. G. de; MENEZES, M. M. de. A artesania de um fazer a prática do trabalho de educadores. Revista Brasileira de Educação, Rio de Janeiro, v. 19, n. 59, p. 967-985, dez. 2014.

ZUCCHETTI, D. T.; MOURA, E. P. G. de. Prática socioeducativa e formação de educadores: novos desafios no campo social. Revista Ensaio: Avaliação Política Pública Educação, Rio de Janeiro, v. 18, n. 66, p. 9-28, jan./mar. 2010.

ZUCCHETTI, D. T.; MOURA, E. Educação além da escola: acolhida a outros saberes. Cadernos Pagu, Campinas/SP, n. 40, p. 629-648, 2010b. Disponível em: http://www.scielo.br/ pdf/cp/v40n140/a1640140.pdf. Acesso em: 20 dez. 2016.

ZUCCHETTI, Dinora T.; MOURA, E. P. G. de; GROPPO, L. A. Apresentação do Dossiê "Práticas de educação não escolar e não formal". Revista Série-Estudos, Campo Grande, v. 21, n. 43, set./dez, p.3-8, 2016. Disponível em: http:/www.serieestudos.ucdb.br/index.php/serie-estudos/article/view/1018.

Acesso em: 2 maio 2017.

Recebido em: 11/7/2017.

Aprovado em: 4/1/2019.

Publicado em: 30/4/2019.

Endereço para correspondência:

Eliana Perez Gonçalves de Moura

Universidade Feevale, ERS 392, no 2755 - Vila Nova

Novo Hamburgo, RS, Brasil

\section{Autores:}

Eliana Perez Gonçalves de Moura

Doutora em Educação/PUCRS, Universidade Feevale. ERS 392, no 2755 ,

Vila Nova, Novo Hamburgo, RS, Brasil.

Orcid: https://orcid.org/0000-0001-7106-0770

E-mail: elianapgmoura@gmail.com

DiNORA TEREZA ZUCCHETTI

Doutora em Educação/UFRGS, Pesquisadora CNPq, Universidade Feevale.

ERS 392, no 2755, Vila Nova, Novo Hamburgo, RS, Brasil.

Orcid: https://orcid.org/0000-0002-7122-1025

E-mail: dinora@feevale.br 